人於芯母多無ナ帽七八色夫

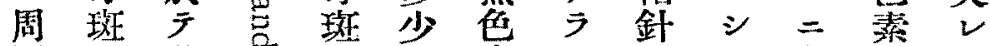

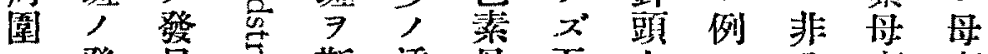
二發見总斯唀早吾大八今斑斑

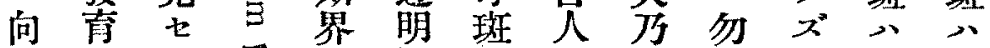

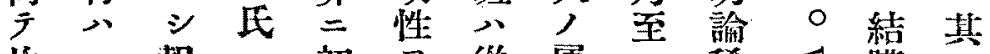
比一報 $八$ 初 $\exists$ 從㯪 $\exists$ 稀 較般告結》有來名》有豆二根

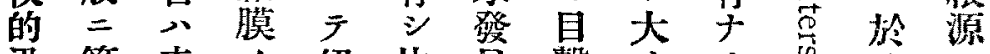

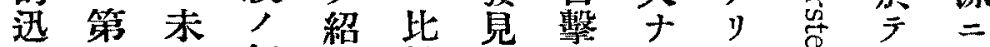

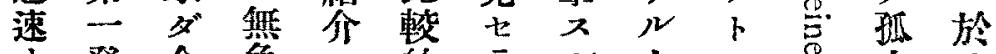
大登余色七的

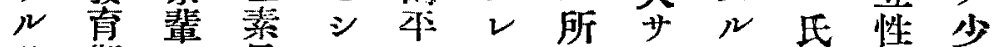

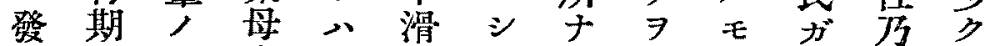
育三耳斑飞三結》有り下至モ

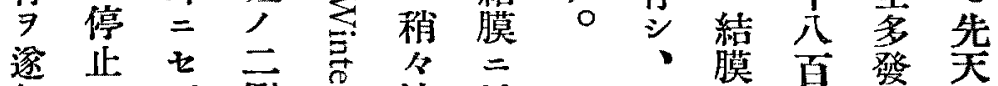
行

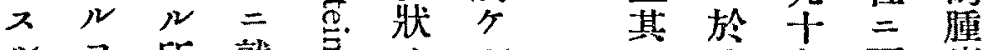

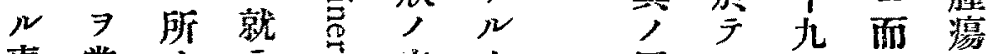
事常于亏表少周八年王三 $ナ r y$ 精 氏面數圍崄三健埭 シ ス。細 卜 寸 七然 $\quad$ 过 $シ$ 例 僅 領 $x^{*}$ 組 周 $八$ ○ド 織 ナ圍 角 尚 $E$ 學 少占 其的、血緣

母; 研次境若

斑一究 鬲 界 定 $\quad \Rightarrow$ 判》

後數落写明

年 $、$ 表苍 $九$ 其

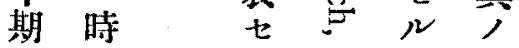

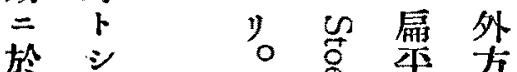

方

モ 春

其 情

, 發

發 動

育 期

八三 管。带

可至斑 $r$ 此 紅

能 次

的 $\checkmark$

习y, 色

デ 角 篮 =

モ其 卓最急 シ

二域:シ於 キ

隆、例 $\bar{z}$

起淚, 副,

鼻如所 =

鮮、キ自 シ

褐 等結 r

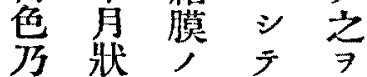

至晹殆發色

暗壁異桑

角

膜

国

牫

褐さドセ舟

色殊 全 5 致

人二部次范

母角三、無

高

斑 膜 亘場色

$\exists=y$ 合 繴

見密于決盘

周

接色 泣

事菏素

至委 稀 區

敢近斑有別

年接,

稀济成少。

清

有方立毛 
眼 リッナ其 角 二 0 う 》。般 膜 母 斑

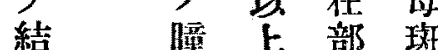

膜

母

琣

爻

有

千

s

モ

,

$=$

非

;

ザ

r

-

既

述

如

格

倘

木

垶

膜

及

虹

彩

$=$

於

"

证

母

斑

モ

四珍

目

$+2$

九

孔范繁

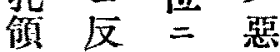

$=$ 皮性

占角 的

在藐結充

相

視斑度

力基鐌

障其胡 。

害, 必

马 所 $E$ 限

起在, 利

七部八何

位容等

モ $=$

, 關

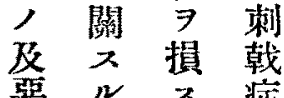

性心公瘤

發固 $=$ 尹

者妇

$\exists y$,

發子此公

越皮,

飞王醜 上

一形子

モ般寻

- 外去

外魏七

治 $\exists$ ע治

瘵害召潦

人篇入

必的,

要 コ治埸

社痖

感僅入極

天少必

$\nu F=\bar{J}$

，灴少

足

今

중

$r=r \quad$

+ $\exists \mu$ 。

₹y, 》
, 除 =

\section{于 事}

絬

膜

生 卓 7

융

命立,

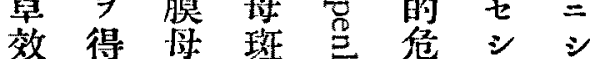

$\exists$ 斑 $\exists$ 。. 險 $x \bar{y}$

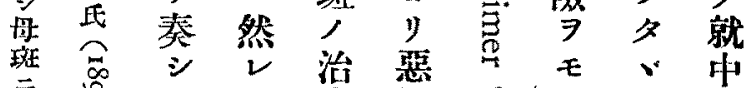

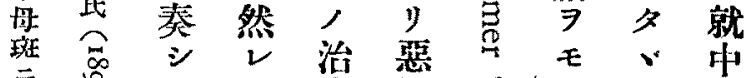
共痖 性 氏與二

宫尘其

肉

例>眼素

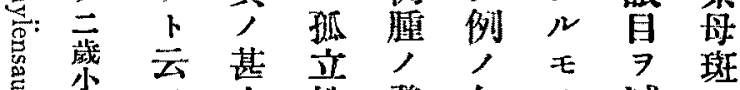

ᄀ夺性登帤子留特

苍

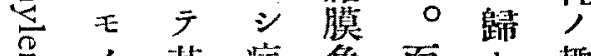
, 其痱角而七趣 二, 例膜 $シ$ 旨

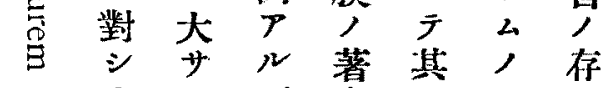

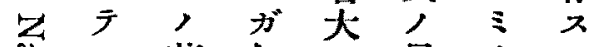

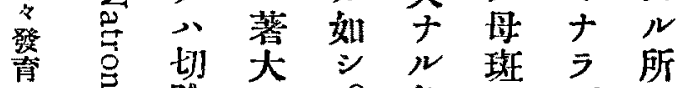
除大。色, ズ王

皮素大、亦

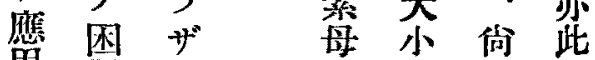
用㣀 x 斑 $尹$ 水, 我 以 一 點 良立般三 性將贫 9 而承腄 ” モ, 停落如 证督多。 性 如身毁 二何能 $\neq$ 經 $\ni$ 他色 過卜部菜 七 $シ \mu$ 轉 班 $v=$

際

$=$ y

$\rightarrow \bar{J}$ 袁谷其

氏 的

大從ミ
离

方

繥

暯

發
毛能移，

玉 少等

アザ木

的該

バへ笑惡

又刎體性

小諭 = 肉

ナ = 對的

此

結 テ生成 
號六十五百二第

㴟本族作 明

- 病 = 往 治

多, 眼症 四

少徍病 者 蕢

眼惩是年

脂 患 シ 令

$r$ 者。眼 月

》等士

診生 $\Rightarrow$ 三

療 乘 患 百

$\Rightarrow$ 健 初

分康 良 殓

○ $=$ 眼

テ 管

埾七

身高。

的亭

著 實 知

患子晸

7 吾

知數少

ラ 日 郡

ズ前御

乾骂

㕛嬠 瀨

眼 症 村

病

7

思

七

i $\quad \Rightarrow$

事當

ナ

カ

y

シ

五 速

三 坌

日 治

前宿

$\exists$

$y$

兩

眼

流

O
余

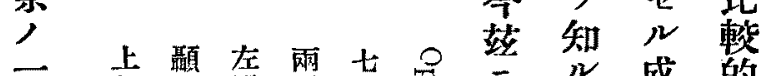

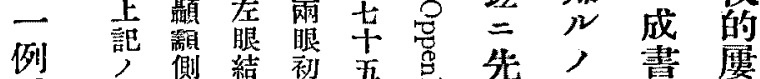

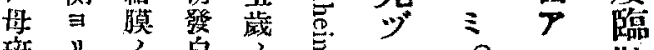

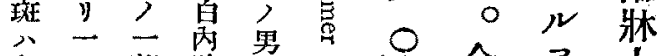

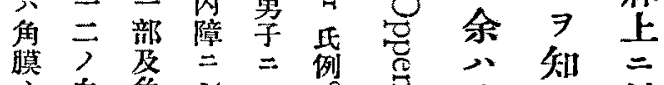

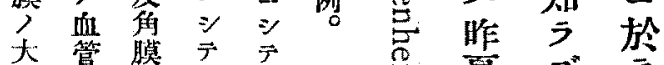

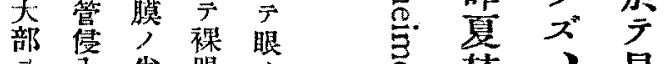

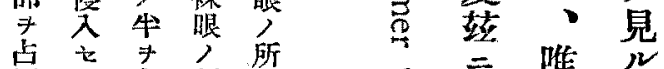

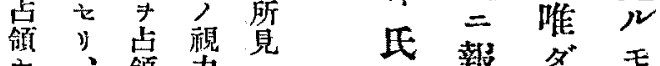

七 㬉力分報ダモ

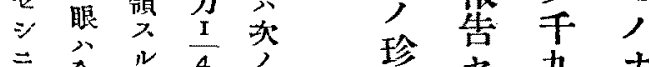

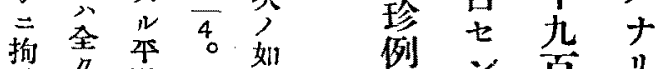

势滑雨留

天゙热消霜

最整桬留

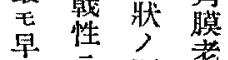

少三粱 炭

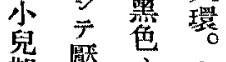

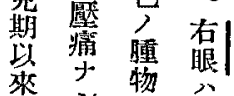

恐 说 $\gamma^{\gamma}$ 烈

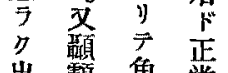

出観 角㗬

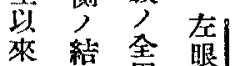

不膜周 留

變 園 瞼

大三八畩

楠齿箅 $\frac{2}{3}$ 箬

○ 雀掩少

虫色 七

者公大

面 少

何贯空”。

等瑟出。

苦 y y

痛 テ。

毛艺此

感王莫

出尔

ザ 血 翼

》管蔣

算

卜 充

穹炎方

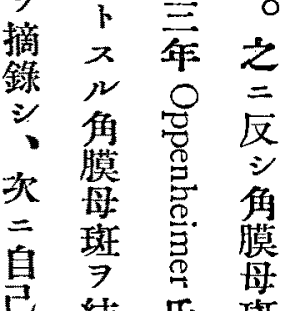

已結氏 琣

蜜膜 ガ

签 炎極

例曢結 メ

$\Rightarrow$ 捍

七膜

今偶,

尗然 目,

。發 斑 =

觉少 シ

入卜テ

ル題 寡

ノシ 聞

機 テナ

會 報 ル

$\Rightarrow$ 告 余

得七 分

夕 シ 未

リーーダ

奇之

例 7

$>$ 記

ル載
記際角 稀 
45 號兵十五百二第 者七界七卜其其尘膜知憸

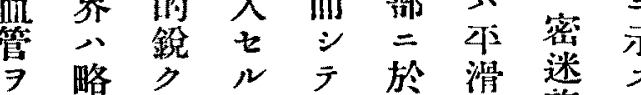

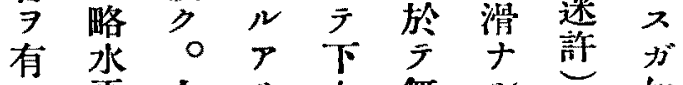

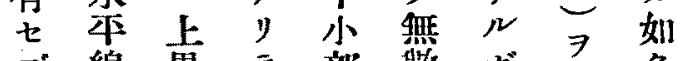
ズ線界 テ 部數 ガ

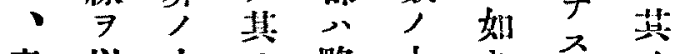
表以大”略小禾尔

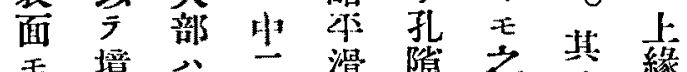

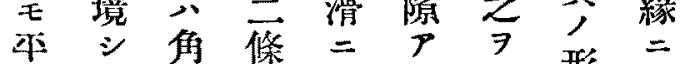
滑之膜只主泙形於 ナ三緣内 り’接三外兄䋐 ス 略嘎

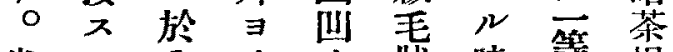
倘ハラリナ狀時等褐

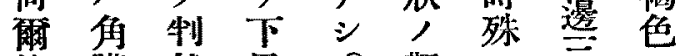
他 膜 然界。觀二言, 八 界 $尹$ 此 $\exists$ 角形腫 母中七走,

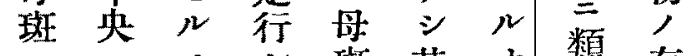
$==モ$ 斑 其ナ䚏 存

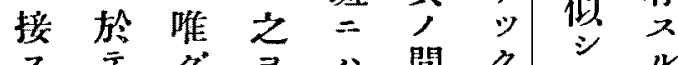

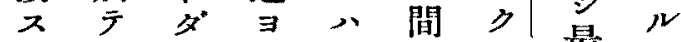
ル稍其》附临氏最 $r$ 部多;枝近 $尹$ 唇り 大 三別結 バル橫テ

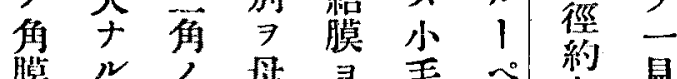

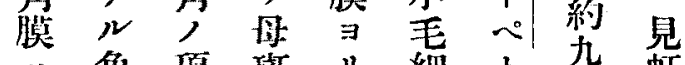
八角頂瑟り細 $卜$ 杂虹 嚾 膜 點 = 圖 血 斜 密 彩 $=$ 溷 $=$ 造 $=$ 管 照迷脱 線 濁相示, 法最出

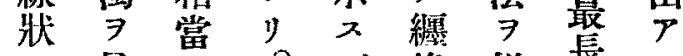

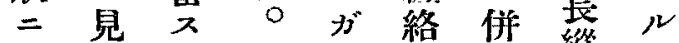

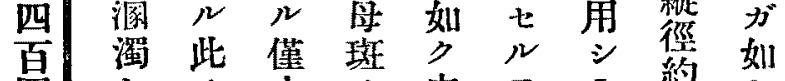
四七, 少, 肉 7 筜手

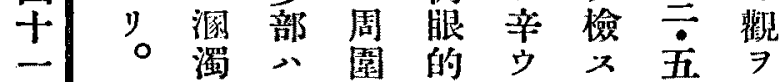
母 只結 二兒シ心密呈

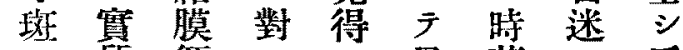

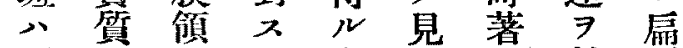

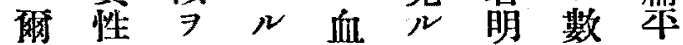




\section{號六十五百二第}

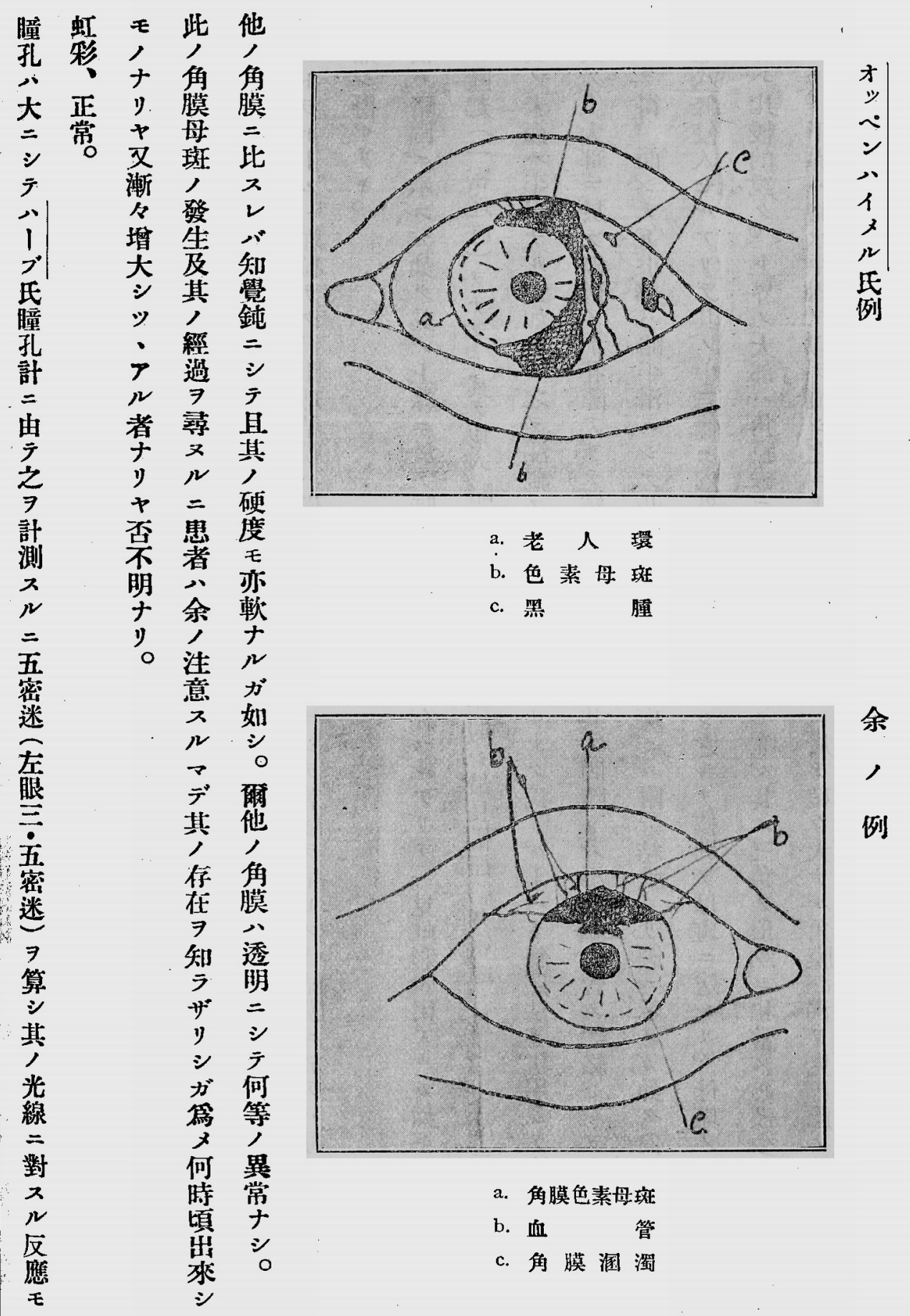


47 號 六十五百二第

岡
余

稀 固本角 八

有 $\exists=$ 膜 最

十 リ 於 目 後

其 $テ$ 斑

者分 $心$ 眼

劣調少關二

査多 ス 於

事奀々ハ占

八充モ文

疑 分 明 獻 甘

$>+$ 治 $\ni$ 斑

$\checkmark$ 四探,

デ シ十究 一

天上年 万般

ナ踓以 ル 知

$\neq$ モ 前 = 見

+ $=$ 桑 $卜$

り、於愿自

× 导

又 吾 角 編 實

面富膜本 驗

= 严 眼 例

於高斑科

元 $=之$ 對

四, 關 證 照

斑一及明

$\therefore$ 例 $2=$ F

一人 報 於 聊

般 外告 $\bar{~}$

二發 絕 發 論

當 見 僄 見 ズ

該

人 $ル N$ 所

唱贯 能 $\rightarrow j$ 能 $r$

二八如 八

對ザ シ ザシ

シ リ

テ シ 又 7 ス

四

苦 7 歐以

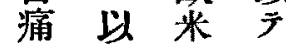

四 $\Rightarrow \overline{5}$,

士 與 見 妾

フレ磨 バ

ル 中 中 现

場 兔 =

合无於 我

僅 角 $\bar{\gamma}$ 日

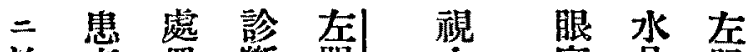
治者䁂斷眼少底晶眼 シ 八 檢 體 二 夕其結 雨 結 》) 膜 良 膜 $<<$ 上硝 シ 、後炎 $=$ 管 角乘三方於 || II 於體稍

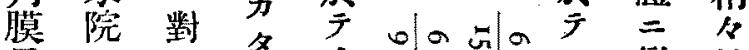

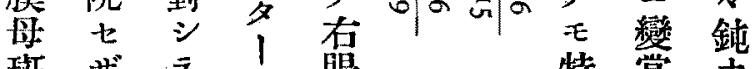
斑ザラル眼 - 特常ナ

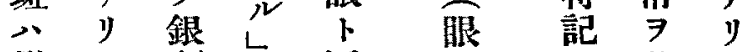
變 シ 洌性同鏡入發。 华ガ少性㧼整心筧 ナ，本點結少適 $\neq$

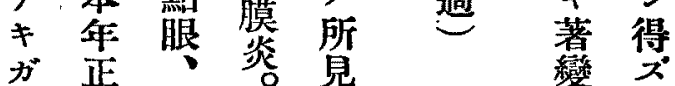
如 正白鼻綮 シ同宅有皮 上人角右外 認 知 云, 卜眼他赑 人妻 シ 有 N

”結示角正能

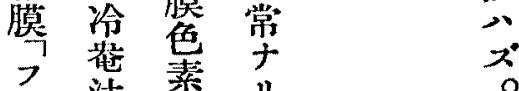

リ藥素 。

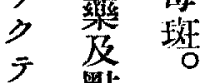

テ 點

ᄂ 眼

9 藥

病 7

ミ投

來 與

院 七

七

際

聞

多

處

$=$

$\exists$

V

-

結

膜

炎

>

速 
樂 時 $y=7$ × 向次二互例或壬少

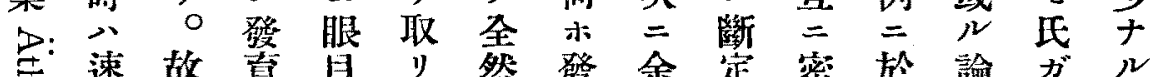

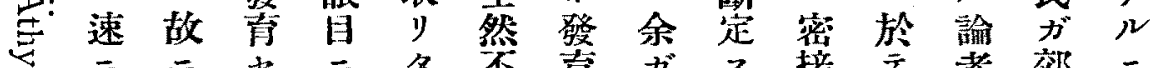

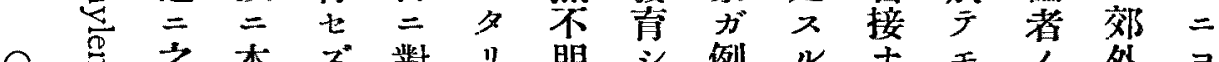

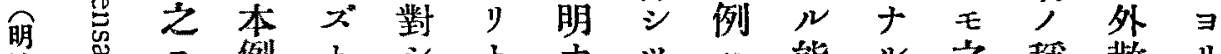
治焉二例 西总對, 踓

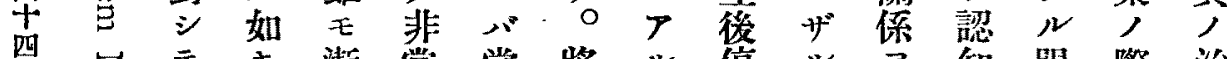

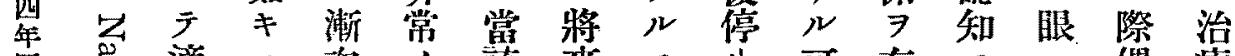

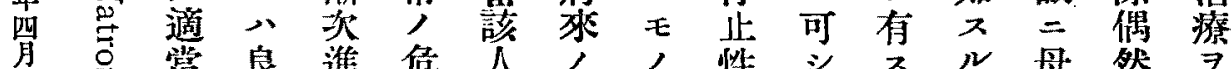
豆官當良進危人,

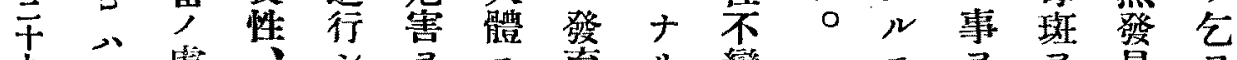
旮文虔、信

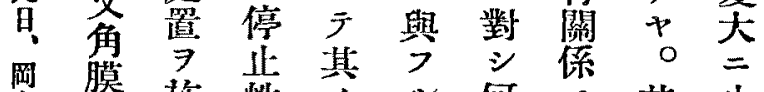
山贯施性方 琣瑟

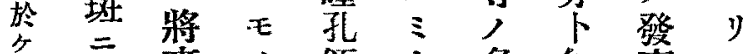

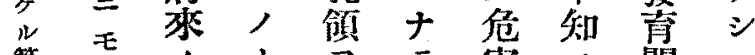
第点ノト

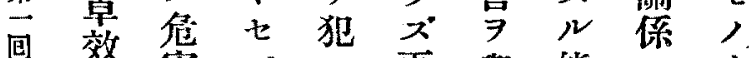
眼 科り $、$ 何 研ヤ本等至生ザル者ヤ

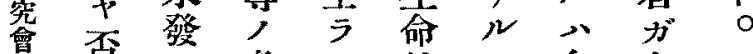
古三遥心的飞多余小

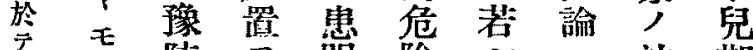
テ將 防 $\ni$ 眼險 河䔩

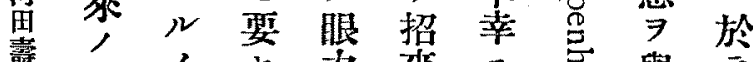

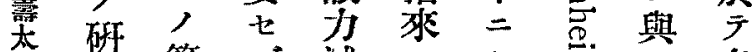
郎究策 $x^{*}$ 減 代 要 蓝 踓 节事惡 民下,

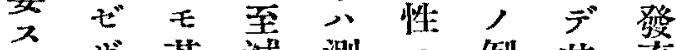
未ザ 洛 滅 測二例 其 壳 決ルジ發,

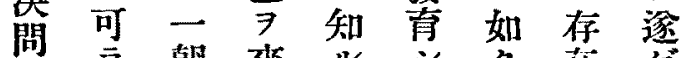
明題 デ 朝 兆 治り ○行や力性認王

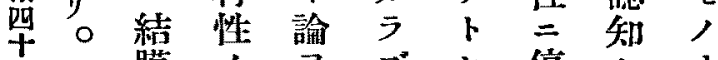
四膜 年毒 徽 待 0 步ザリ

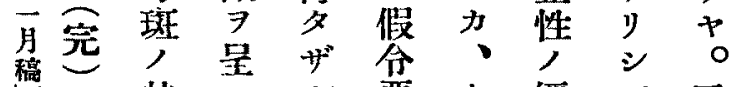

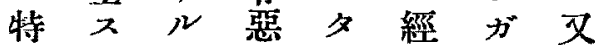
效ル十性、過鼡令
E $\rightrightarrows$ 見

ノ得有七七

十多不至

リリルモ砝

+ E

集然, ‘

中余文

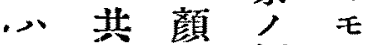
将桨 面 例 其

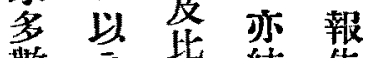
敘 示此 結 告

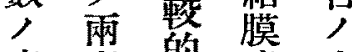
症者 的资少 例, 結,

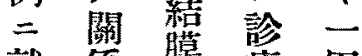
就係 臆療因 テ $7=$ 厂 統明气際 計 日 的 $=$ テ シ 砸 ス 夏發。 管 $\Rightarrow$ 能 斑 七未 ナ $\gg$ $* 0$ シ ザ 合モ号 タル佯, 导

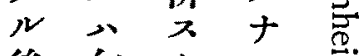
後分上点 論云 バ 非 二 ブた ラ シ 關 リ ザ ᄂ 兩 心光 心者 余如 遽北方 